\title{
An Analysis of the Association of Trauma Centers with Per Capita Hospitalizations and Death Rates from Injury
}

Robert Rutledge, M.D., Samir M. Fakhry, M.D., Anthony Meyer, M.D., George F. Sheldon, M.D., and Christopher C. Baker, M.D.

From the Department of Surgery, University of North Carolina at Chapel Hill School of Medicine, Chapel Hill, North Carolina

\section{Objective}

This study used population-based data bases to assess the association of trauma centers with per capita county hospitalization and trauma death rates in the State of North Carolina.

\section{Summary Background Data}

The current study extended previous work using two North Carolina data bases to assess the association of the presence of a trauma center with per capita county trauma death rates.

\section{Methods}

Data on per capita county trauma hospitalizations and deaths were obtained from the state hospital discharge data base and the North Carolina Medical Examiner's data base. Bivariate and multivariate analysis techniques were used. The dependent variables of interest were prehospital, hospital, and total trauma death rates and hospitalization rates for injury.

\section{Results}

Bivariate analysis identified a number of factors associated with per capita county hospitalizations and trauma death rates. These included the per cent unemployment, racial distribution, county alcohol tax receipts, and advanced life support certified emergency medical services providers. The per capita trauma death rates were significantly lower in counties with trauma centers compared with those without trauma centers $(4.0 \pm 0.5$ and $5.0 \pm 1.1$ deaths per 10,000 population, $p=0.0001$, respectively). The per capita hospitalizations for trauma were also lower in counties with trauma centers. Multivariate modeling showed that the presence of a trauma center and advanced life support providers were the best predictors of decreased per capita county trauma death rates.

\section{Conclusions}

The study showed that the presence of a trauma center and advanced life support training were the two medical system factors that were the best predictors of the per capita county prehospital and total trauma death rates. These findings are consistent with the hypothesis that trauma centers are associated with a decrease in trauma death rates. 
Trauma remains one of America's most devastating public health problems. ${ }^{1}$ Trauma centers have been designed to decrease the morbidity and mortality of injury through the development of regional trauma systems. Unfortunately, the increased expense of maintaining trauma centers and the poor reimbursement associated with trauma care have led fewer hospitals to seek a trauma center designation, and a number of trauma centers have allowed their designation to lapse. ${ }^{2,3} \mathrm{Al}$ though there are data that support the value of trauma centers and justify the investments needed to maintain trauma centers, most of these do not involve large population-based studies. Large-scale randomized clinical trials are impractical for various reasons, including costs, set referral patterns, the heterogeneous nature of trauma, and the ethical concerns of performing such a study. ${ }^{4}$

The current study is based on previous work that used the statewide population-based North Carolina Medical Examiner's data base and the University of North Carolina Health Research data base to assess the association of the presence of a trauma center with per capita county trauma death rates. ${ }^{5}$ It extends the previous analysis by accessing another statewide data base, the North Carolina Medical Database Commission Database (NC MDCD) to determine the association of trauma centers with county per capita hospitalizations and hospital deaths from trauma. Because the previous study demonstrated that the presence of a trauma center is not the only factor associated with county per capita trauma death rates, a number of other demographic and medical system factors that might have an impact on per capita trauma hospitalizations and death rates were also evaluated. The primary hypothesis tested in this study was that the per capita county hospitalization and death rates for injury would be lower in counties with trauma centers than in counties without trauma centers.

\section{MATERIALS AND METHODS}

\section{The Trauma Centers of North Carolina}

The State of North Carolina began designating trauma centers through the Office of Emergency Medical Services in 1982. The criteria for trauma center designation closely paralleled the criteria established by the American College of Surgeons. ${ }^{6}$ Of the eight trauma centers in North Carolina, five are level I, and three are level II.

\footnotetext{
Presented at the 113th Annual Scientific Session of the American Surgical Association, Baltimore, Maryland, April 1-3, 1993.

Address reprint requests to Robert Rutledge, M.D., Associate Professor of Surgery, UNC General Surgery, CB\# 7210 Burnett-Womack, Chapel Hill, NC 27599.

Accepted for publication April 9, 1993.
}

Regardless of the level, each hospital must meet essential criteria (verified by a written request for proposal and an in-depth site visit) before designation and routinely undergo renewal visits.

\section{Study Population}

The population selected for this study was North Carolina trauma patients who were injured and admitted to hospitals in North Carolina or who died of an injury in the state. Patients who fulfilled these criteria were included as the study population. North Carolina is the tenth most populous state in the nation and has large rural and urban populations ( 80 counties are rural, and 20 are urban). In addition, a significant portion of its population are minorities $(21 \%)$ or the poor $(7 \%)$, for whom trauma is a more common problem. During the years 1988 through 1991, there were 13,100 trauma deaths in North Carolina; $60 \%$ of those who died were boys and men with $40 \%$ girls and women (average age, $26 \pm 10$ years).

\section{Data Sources}

\section{North Carolina Medical Examiner's Data Base}

Data on the number and characteristics of trauma deaths for this study were obtained for the years 1988 through 1991 from the North Carolina Medical Examiner's data base. This is a long-standing, well-validated, population-based data base that collects information on every trauma death in the state of North Carolina. This data base has been extensively used and has been confirmed as an accurate population-based tool in numerous studies. $^{7-9}$

\section{North Carolina Medical Database Commission Database}

Data on all hospitalizations from injury in North Carolina are sent to the NC MDCD. These hospital discharges are coded by International Classification of Disease ninth revision (ICD-9) diagnoses and procedures and entered into a state-mandated hospital discharge data base. Patient outcome is available for analysis.

\section{University of North Carolina Department of Surgery Health Research Data Base}

Data on county variables, including geographic, socioeconomic, and county medical system factors, were obtained from a combined data base developed and stored at the Department of Surgery at the University of North Carolina at Chapel Hill. This data base contains demographic and medical system data on the State of North Carolina consolidated from several population-based national and statewide sources. 


\section{Variables}

\section{Dependent Variables}

The dependent variables of interest for this study were the per capita hospitalizations for injury and prehospital, hospital, and total trauma death rates in each of North Carolina's 100 counties. The per capita values were obtained by determining the number of trauma deaths (including prehospital, hospital, and total trauma deaths), dividing this number by the county population, and multiplying it by 10,000 (per capita county trauma death rate $=$ [resident trauma deaths/number of county residents] $\times 10,000)$. The per capita county hospitalization rate for injury was determined in a similar fashion (per capita county hospitalization rate $=$ [resident hospitalizations/number of county residents] $\times 10,000$ ).

\section{Independent Variables Tested}

The independent variables were divided into three groups (Table 1). The groups were (1) geographic variables (including county population density and per cent of county area that was rural); (2) socioeconomic variables (including mean personal income and unemployment levels in the county, the per cent of the county population that was not white, and the county alcohol tax receipts); and (3) county medical system factors (including the presence or absence of a trauma center, the level of emergency medical services [EMS] certification in the county, i.e., advanced life support [ALS] or basic life support [BLS]), the presence of 911 emergency telephone access, the number of general surgeons in the

Table 1. LIST OF VARIABLES

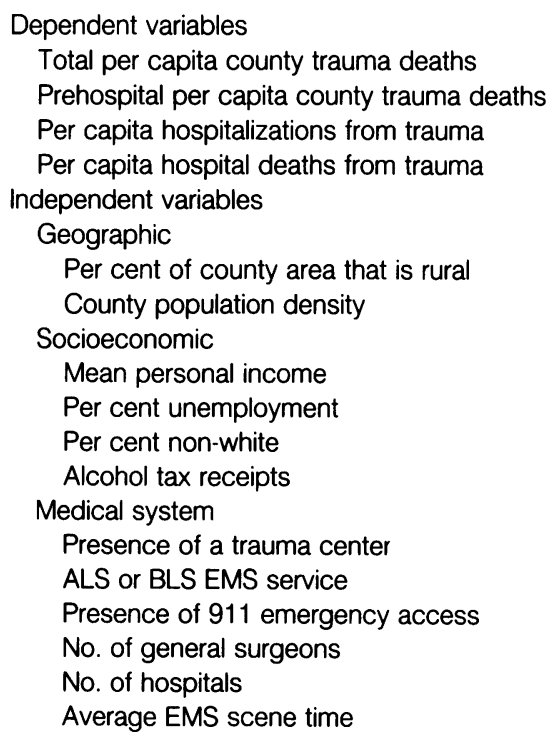

county, the number of hospitals in the county, and the county average EMS scene time).

\section{Statistical Methods}

Bivariate analysis was performed as the first step in an attempt to determine the association of the multiple independent variables with the dependent variables ( per capita hospitalizations, prehospital and hospital deaths, and total county trauma death rate). Pearson correlation coefficients were derived for each independent and dependent variable. The mean per capita trauma death rates were grouped by the values of the categoric variables (presence of a trauma center, EMS certification, and presence of 911 telephone access). These were then compared using Student's $t$ test when they were dichotomous or analysis of variance when they were not. For comparison purposes, the categoric variables were transformed to numeric variables, coded as 0 and 1 , and used in the bivariate correlation analysis with the other candidate variables (trauma center $=1$, no trauma center $=0$; $\mathrm{ALS}=1, \mathrm{BLS}=0$; and $911=1$, no $911=0$ ).

After bivariate analysis, multiple linear regression analysis was performed. To avoid problems with multicolinearity, variables with a high degree of correlation with one another were excluded from multivariate modeling. Linear regression was performed using stepwise selection to build a model to predict the value of the each of the dependent variables. Testing of the regression model was performed to identify problems such as multicolinearity, heteroskedasticity, and autocorrelation using a statistical analysis system for personal computers (SAS, Cary, NC) program. Residuals were plotted, and standard tests of influence, including Cook's D, were analyzed to discover whether any observations were outliers. These diagnostics showed that the assumptions of linear regression held.

\section{RESULTS}

\section{Population Description}

The population distribution, the distribution of the absolute number of trauma deaths in each county, the distribution of the per capita county trauma death rates, and the location of this state's trauma centers are shown in the maps in Figures 1 to 5. During the time of the study, there were an average of 37,000 hospital admissions for injury per year, 3500 total trauma deaths per year, and 1100 hospital trauma deaths per year.

\section{Bivariate Analysis}

Counties with trauma centers were more urban in population $(251,000 \pm 156,000$ vs. $52,000 \pm 46,000, p=$ 


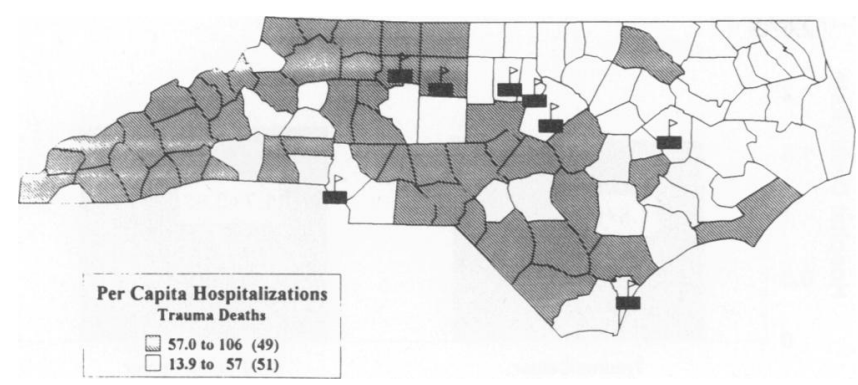

Figure 1. Per capita hospitalizations for trauma.

$0.007)$ and had more total trauma deaths $(309 \pm 190 v s$. $78 \pm 67, p=0.01$ ). Trauma center counties had more total hospitalizations for trauma and more hospital trauma deaths $(5337 \pm 3208$ vs. $1181 \pm 943$ and $122 \pm$ 70 vs. $27 \pm 25, \mathrm{p}<0.01$ in both, respectively). The mean trauma death rate in counties with trauma centers was significantly lower than that in those without trauma centers $(4.0 \pm 0.5$ and $5.0 \pm 1.1$, respectively; $p=0.001$; Figs. 6 to 8). When analyzed on a per capita basis, trauma center counties had a trend toward lower hospitalizations ( $51.3 \pm 7 v$ s. $57.7 \pm 17$, respectively, $p=0.07)$ and had the same per capita hospital death rate $(1.6 \pm 0.4$ vs. $1.7 \pm 0.7$, respectively; $p=0.5$; Fig. 9 ). The most significant difference was in the prehospital death rate in trauma center counties $(2.3 \pm 0.3$ vs. $3.2 \pm 1.3$, respectively; $p=0.0001$ ). A comparison of prehospital and hospital death rates in the counties with ALS versus BLS certified EMS showed that counties with ALS certification had significantly lower prehospital death rates $(2.9$ \pm 1.0 vs. $4.1 \pm 1.3$, respectively; $\mathrm{p}=0.0002$ ) and slightly higher hospital death rates $(1.8 \pm 0.6 v s .1 .5 \pm 0.7$, respectively; $p=0.05$; Fig. 10). Bivariate analysis revealed a number of significant associations between the independent and dependent variables (Table 2). Of the demographic factors that were tested, the county racial distribution, unemployment levels, population density, and alcohol tax receipts were found to be associated with county per capita trauma death rates.

\section{Medical System Factors}

Of the medical system factors studied, neither the number of surgeons nor the number of hospitals in a

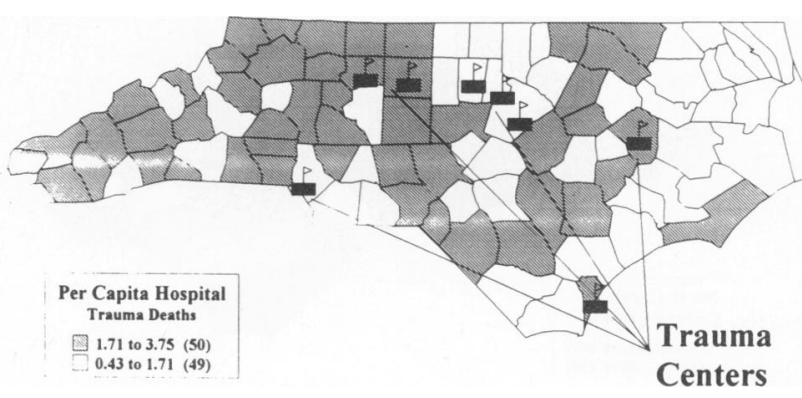

Figure 3. Per capita hospital trauma deaths.

county were significantly associated with trauma death rates. The EMS scene time was associated with trauma death rates but in the opposite direction than expected, that is, as the scene time increased, the per capita prehospital death rate decreased, hospital deaths increased, and total deaths decreased. County ALS certification and the presence of a trauma center were associated with prehospital, hospital, and total trauma deaths. Counties with ALS certification had lower prehospital trauma death rates, higher hospital death rates, and lower total trauma death rates (Table 2).

\section{Multiple Linear Regression}

Multiple regression analysis with ordinary least squares was used to assess the relationship of the independent variables of the study with the dependent variables (per capita county trauma hospitalizations and trauma death rates). This technique was used to build a mathematic model of the dependent variables using selected independent variables to explain the variation in the dependent variables. Because misapplication of this technique can lead to erroneous results, the steps in creating and testing the regression model are detailed subsequently. Regression modeling was performed for each of the four dependent variables in the study (county per capita hospitalizations, prehospital trauma deaths, hospital trauma deaths, and total trauma deaths).

Multiple regression was performed selecting those candidate variables that were shown to be strongly associated with outcome by the bivariate analysis. The steps

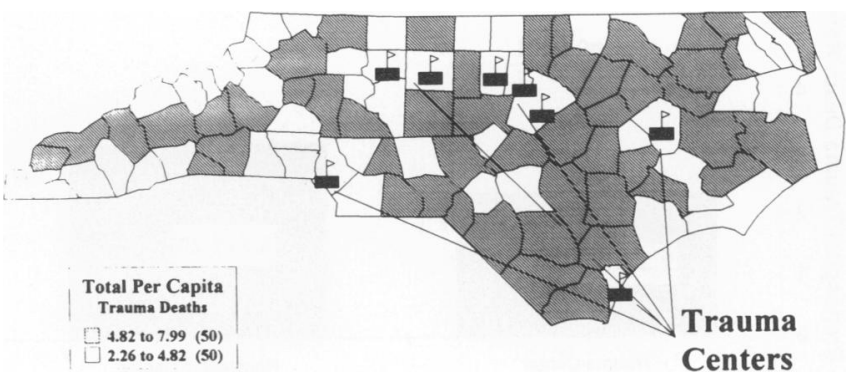

Figure 4. Total per capita trauma deaths.

Figure 2. Per capita prehospital trauma deaths. 


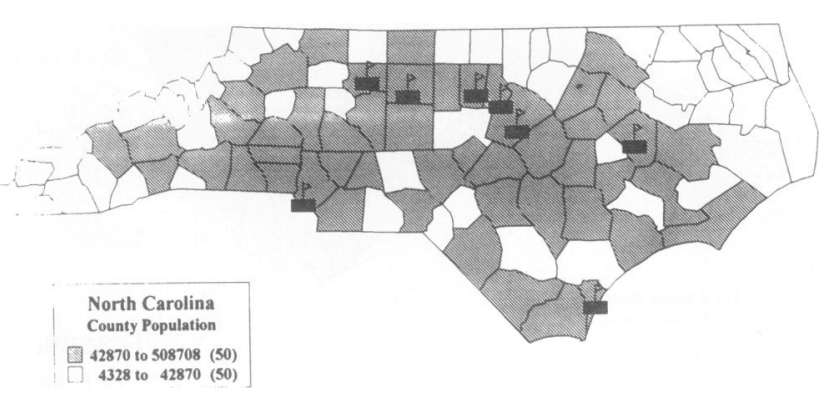

Figure 5.

and results of stepwise multiple regression are shown in Tables 3 to 6 .

\section{Prehospital Trauma Deaths}

Prehospital trauma death rates were best predicted using a model that included the per cent of the nonwhite population, the county alcohol tax receipts from the demographic data, the level of EMS training, and the presence of a trauma center (Table 3 ).

\section{Hospital Trauma Deaths}

Hospital trauma death rates were best predicted using a model that included measures of poverty (per cent unemployment and mean personal income), racial distribution, and one medical system factor, the presence of a trauma center (Table 4).

\section{Total Trauma Deaths}

The total trauma death rates were best predicted using a model that included a variety of demographic and medical system factors. County alcohol tax receipts, racial distribution, and per cent unemployment were all selected for the model. The EMS level of training and the presence of a trauma center were the medical system factors selected as the best model predictors from the medical system factors tested.

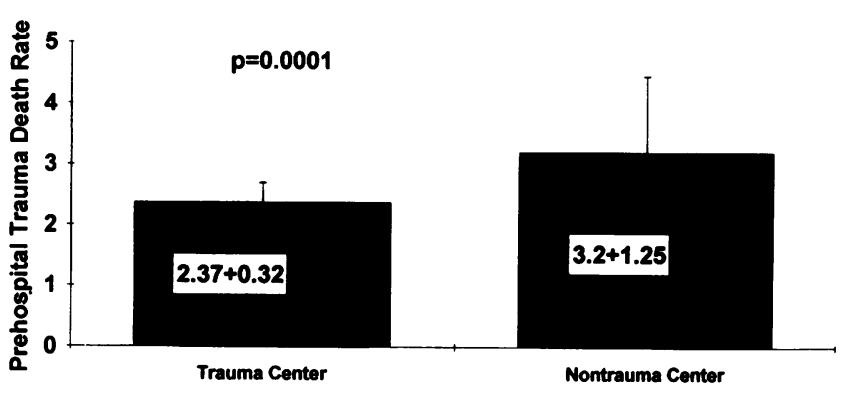

Figure 6.

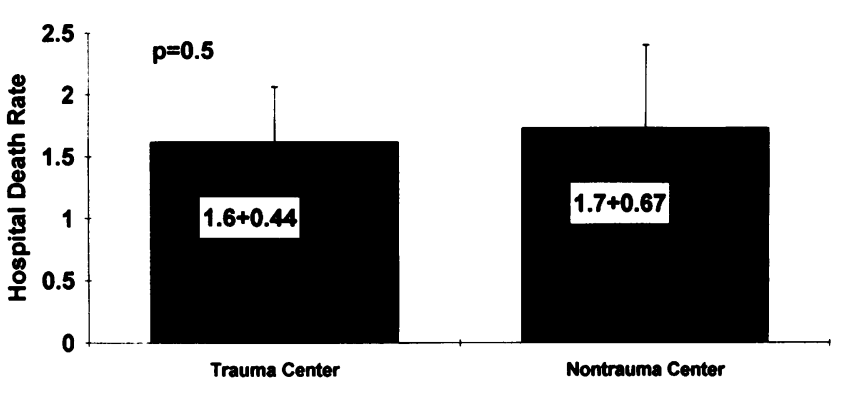

Figure 7.

\section{Hospitalizations for Trauma}

Modeling of the county per capita hospitalization rate for injury identified a variety of predictors of county hospitalization rates. Although a larger nonwhite population in a county was a predictor of an increased prehospital and hospital death rate injury, it was also a predictor of a lower hospitalization rate for injury. Increased county per cent unemployment and increased mean county personal income were predictors of increased per capita hospitalization rates for injury. Decreased population density was a predictor of increased hospitalization rates. Two medical system factors were found to be additive predictors of hospitalization rates. Counties with hospitals and those with ALS level EMS were likely to have higher hospitalization rates. The addition of a trauma center to the model did not improve the predictive power of the model.

\section{DISCUSSION}

Because of the serious nature of injury as the most common killer of young adults and the third most common cause of death among Americans, trauma has been receiving increased attention as an important public health issue. ${ }^{10}$ The development of hospital trauma centers has been a critical approach for decreasing the morbidity and mortality of injury. Unfortunately, being

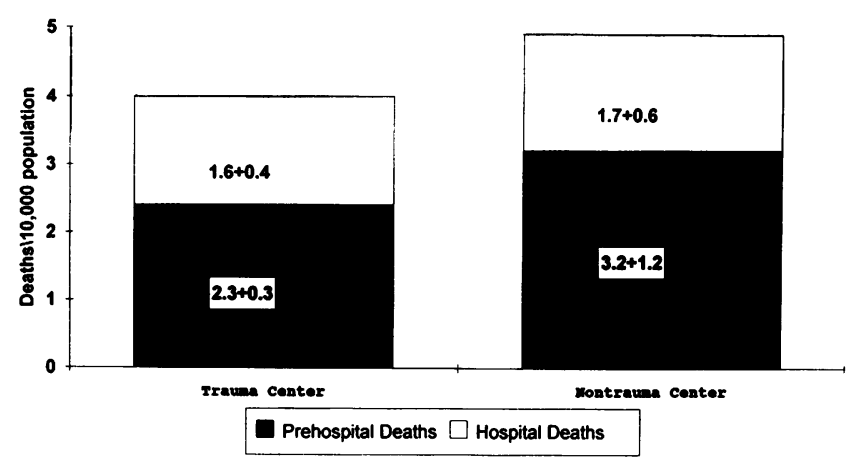

Figure 8. 


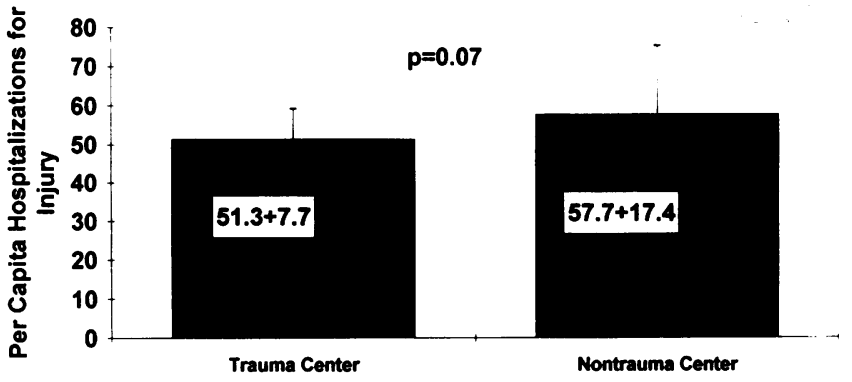

Figure 9.

identified as a trauma center can have disastrous financial consequences. ${ }^{10-16}$ Economic factors have led to negative repercussions for those hospitals that continue to invest the necessary personnel and material resources required to provide care for the seriously injured. ${ }^{16-20}$ Care of the trauma patient is expensive and poorly reimbursed. One study estimated that, in 1988, the average cost of a trauma case was $\$ 12,000$ compared with $\$ 4130$ per admission in a hospital for other acute care admissions. ${ }^{3,21}$ Trauma center losses ranged from $\$ 100,000$ to more than $\$ 7$ million. If the nation is to commit itself to the financial support of trauma care, it is necessary to provide solid information demonstrating the benefit of this investment.

Although several studies have demonstrated the positive impact of a trauma center on trauma deaths, ${ }^{17}$ only a few large-scale, population-based studies have been performed. ${ }^{10-15,22-24}$ The purpose of our current study was to extend previous work that used the North Carolina Medical Examiner's data base and the University of North

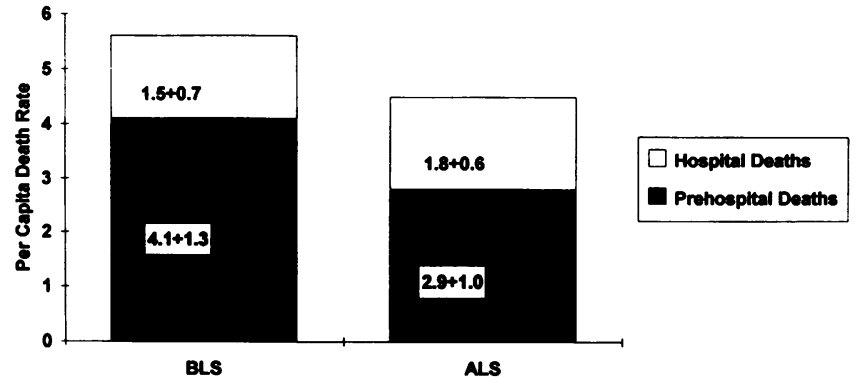

Figure 10.

Carolina Health Research data base ${ }^{5}$ to compare county trauma death rates with a variety of factors that might affect outcome. The current study accesses another statewide, population-based data base, the NC MDCD, which tracks the hospital outcome of all hospitalized patients in the state. This permitted information on hospitalization rates to be included in the study. Discharge information on all patients admitted for trauma (ICD-9 codes 800 to 959.9 ) was obtained for analysis. Hospitalization, hospital death, and prehospital death rates were calculated for injury in each of the counties of the state. These values were then used to determine the association between the presence of a trauma center and trauma admissions and outcomes.

North Carolina is the tenth most populous state in the nation, and it has large areas of both rural and urban populations. A significant portion of its population is comprised of the poor or minorities, but it also contains some of the fastest growing urban areas in the nation. Because of this, examining the entire population base in

Table 2. RESULTS OF BIVARIATE ANALYSIS

\begin{tabular}{|c|c|c|c|c|c|}
\hline Variable & Mean \pm SD & $\begin{array}{l}\text { Prehospital } \\
\text { Trauma } \\
\text { Deaths } \\
\text { (Pearson r) }\end{array}$ & $\begin{array}{c}\text { Hospital } \\
\text { Trauma } \\
\text { Deaths } \\
\text { (Pearson r) }\end{array}$ & $\begin{array}{c}\text { Total } \\
\text { Trauma } \\
\text { Deaths } \\
\text { (Pearson r) }\end{array}$ & $\begin{array}{l}\text { Hospitalizations } \\
\text { (Pearson r) }\end{array}$ \\
\hline Avg. personal income & $8850 \pm 1476$ & $-0.19^{\star}$ & $0.31^{\star}$ & -0.02 & 0.18 \\
\hline \% Unemployment & $4.2+9.9$ & 0.12 & 0.15 & $0.22^{*}$ & 0.15 \\
\hline$\%$ Non-white & $23+16$ & $0.44^{\star}$ & $-0.25^{\star}$ & $0.33^{\star}$ & $-0.34^{\star}$ \\
\hline$\%$ Rural & $73+24$ & 0.11 & -0.01 & 0.11 & -0.02 \\
\hline Pop. density & $132+147$ & $-0.21^{\star}$ & 0.05 & $-0.20^{\star}$ & -0.06 \\
\hline Alochol tax receipts (\$/person) & $27+28$ & $0.28^{\star}$ & -0.13 & $0.23^{\star}$ & -0.13 \\
\hline No. of surgeons & $7+14$ & -0.16 & -0.01 & -0.15 & -0.05 \\
\hline No. of hospitals & $1.3+1.1$ & -0.14 & 0.10 & -0.08 & 0.10 \\
\hline EMS scene time & $14.6+4.7$ & $-0.32^{\star}$ & $0.20^{*}$ & $-0.23^{*}$ & $0.20^{\star}$ \\
\hline 911 & $\begin{array}{l}911=15 \\
\text { No } 911=62\end{array}$ & -0.19 & -0.08 & $-0.27^{\star}$ & -0.13 \\
\hline ALS certification & $\begin{array}{l}\mathrm{ALS}=76 \\
\mathrm{BLS}=24\end{array}$ & $-0.43^{\star}$ & $0.19^{\star}$ & $-0.36^{\star}$ & $0.22^{*}$ \\
\hline Trauma center & $\begin{array}{l}\text { TCenter }=8 \\
\text { Non-TC }=92\end{array}$ & $-0.19^{\star}$ & -0.04 & $-0.23^{\star}$ & -0.10 \\
\hline
\end{tabular}


Table 3. MODEL FOR PER CAPITA PREHOSPITAL TRAUMA DEATHS

\begin{tabular}{lccccc}
\hline Variable & No. In & $\begin{array}{c}\text { Parameter } \\
\text { Est. }\end{array}$ & Partial R2 & Model R2 & F Statistic \\
\hline \% Non-white & 1 & 2.06 & 0.196 & 0.196 & 23.8 \\
ALS/BLS & 2 & -0.78 & 0.068 & 0.263 & 0.0001 \\
Alcohol & 3 & 0.009 & 0.040 & 0.304 & 0.004 \\
Trauma center & 4 & -0.812 & 0.031 & 0.0335 & 0.02 \\
\hline
\end{tabular}

Table 4. MODEL FOR PER CAPITA HOSPITAL TRAUMA DEATHS

\begin{tabular}{lccccc}
\hline \multicolumn{1}{c}{ Variable } & No. In & $\begin{array}{c}\text { Parameter } \\
\text { Est. }\end{array}$ & Partial R2 & Model R2 & F Statistic \\
\hline Average income & 1 & 0.18 & 0.100 & 0.100 & 10.9 \\
\% Unemployment & 2 & 14.6 & 0.053 & 0.153 & 0.0 \\
Trauma center & 3 & -0.44 & 0.038 & 0.191 & 0.01 \\
\% Non-white & 4 & -0.65 & 0.026 & 0.217 & 0.03 \\
\hline
\end{tabular}

Table 5. MODEL FOR TOTAL PER CAPITA TRAUMA DEATHS

\begin{tabular}{|c|c|c|c|c|c|c|}
\hline Variable & No. In & $\begin{array}{c}\text { Parameter } \\
\text { Est. }\end{array}$ & Partial R2 & Model R2 & F Statistic & p Value \\
\hline ALS/BLS & 1 & -0.56 & 0.127 & 0.127 & 14.2 & 0.0003 \\
\hline Alcohol & 2 & 0.007 & 0.048 & 0.175 & 11.1 & 0.01 \\
\hline Trauma center & 3 & -0.834 & 0.039 & 0.213 & 4.7 & 0.03 \\
\hline$\%$ Non-white & 4 & 1.33 & 0.028 & 0.242 & 3.5 & 0.06 \\
\hline$\%$ Unemployment & 5 & 18.8 & 0.027 & 0.269 & 3.4 & 0.06 \\
\hline
\end{tabular}

Table 6. MODEL FOR TOTAL PER CAPITA TRAUMA HOSPITALIZATIONS

\begin{tabular}{|c|c|c|c|c|c|c|}
\hline Variable & No. In & $\begin{array}{l}\text { Parameter } \\
\text { Est. }\end{array}$ & Partial R2 & Model R2 & F Statistic & p Value \\
\hline$\%$ Non-white & 1 & -21.5 & 0.115 & 0.12 & 12.8 & 0.0005 \\
\hline$\%$ Unemployment & 2 & 514 & 0.078 & 0.19 & 9.5 & 0.003 \\
\hline Average income & 3 & 3.6 & 0.035 & 0.23 & 4.4 & 0.04 \\
\hline Pop. density & 4 & -0.04 & 0.024 & 0.25 & 3.1 & 0.08 \\
\hline ALS/BLS & 5 & 6.3 & 0.021 & 0.27 & 2.7 & 0.1 \\
\hline No. of hospitals & 6 & 2.7 & 0.0175 & 0.29 & 2.3 & 0.1 \\
\hline
\end{tabular}


North Carolina provides a valuable view of a broad spectrum of traumatic injury. Although the positive impact of trauma centers has been demonstrated in several studies comparing outcome in individual hospitals, ${ }^{25}$ few other studies have evaluated the impact of trauma centers on the outcome in an entire state with multiple trauma centers in a population-based study. ${ }^{5,25}$

This study builds on previous work ${ }^{5}$ by adding hospitalization rates as an additional independent variables. There has been a concern in other areas of medicine about possible overuse and excess costs of subspecialty care. The fear is that, if a resource is made available, it will be used whether or not it is needed, resulting in overuse and overexpenditures. In this study, it was found that, although trauma center counties had a higher overall number of hospital admissions for injury, they had a slightly lower per capita hospital admission rate for injury than nontrauma center counties $(51 \pm 7.7 v s .57 .7 \pm$ $17.4, p=0.07$, respectively). Thus, the use of the specialized care of the trauma center did not appear to be overused by county residents. If anything, it appeared that the residents of counties with trauma centers could be expected to be admitted less frequently than were residents of nontrauma center counties.

Bivariate analysis showed that counties with trauma centers have lower total per capita trauma death rates, but the question remains, "Is the difference in trauma death rates seen in trauma center and nontrauma center counties related to the presence of the trauma center or are other factors at work?" A variety of demographic factors may affect trauma death rates. Other studies have shown increased trauma death rates in poor and minority populations. ${ }^{26-30}$ Susan Baker et al. ${ }^{31}$ noted that rural-urban factors are important county features that are associated with trauma death rates. Using bivariate analysis, the current study showed that population density, per cent nonwhite, per cent unemployment, and personal income were all associated with total per capita county trauma death rates. These associations were documented in our previous work. ${ }^{5}$

The current study was also designed to assess the association of other medical system factors with trauma hospitalizations and prehospital, hospital, and total trauma death rates. Medical resource variables tested included a variety of both prehospital and hospital factors. Prehospital factors tested included the presence of ALS training and the presence of 911 telephone access. Previous studies by our group analyzed both these factors. $^{27,28}$

\section{County ALS Certification and Trauma Outcome}

By contrast with the results of other studies reported in the literature, ${ }^{32,33}$ our previous work found that the pres- ence of ALS is associated with decreased total trauma mortality rates. ${ }^{27}$ The current study again demonstrated that ALS counties had lower total trauma death rates and that ALS was the most powerful predictor of decreased total per capita trauma death rate in the multivariate analyses. This study extended the previous work by assessing the association of county ALS certification with county prehospital and hospital death rates. Investigation into county prehospital and hospital death rates clarified where the effect of ALS occurred. The results demonstrated that ALS certification was associated with a significant decrease in the county prehospital death rate but that the hospital death rates in ALS counties were increased slightly. A possible explanation for this finding is that, if prehospital care such as that provided by EMS, is effective, its impact would be in the prehospital arena where the intervention occurs. ALS interventions might prolong the lives of a number of critically ill patients who would otherwise die at the scene or during transport and, thus, not be admitted to the hospital. Some of these critically ill patients might later die in the hospital and increase the hospital's mortality rate. Although this explanation could not be confirmed by the data available in our current study, the supposition that the effect of EMS was greatest in the prehospital phase of trauma seemed to be logical.

\section{Trauma Centers and Trauma Death Rate}

The primary goal of this study was to assess the association of trauma centers with trauma hospitalizations and death rates. Bivariate analysis demonstrated that the mean trauma death rate in counties with trauma centers $(4.0 \pm 0.5)$ was significantly lower than that in nontrauma centers $(5.0 \pm 1.1, \mathrm{p}=0.001)$. These findings were similar to those in our previous work. A new finding was that the majority of this change in outcome was found in the decrease in the prehospital death rate.

The problem with bivariate analysis as an analysis technique is that it does not account for confounding factors, and with regard to trauma center counties, there may be other factors that contribute to the differences in trauma death rates. Trauma center counties are generally more urban, have a higher percentage of minorities, higher mean personal incomes, and higher population densities. All these factors might affect the per capita trauma death rate, and the presence of a trauma center may only be an indicator of the presence of other factors. In addition, it may not be the trauma center designation per se but other hospital resources that are affecting the per capita trauma death rate. For example, it could be that increased hospital size, larger emergency departments, more hospital admissions, a larger staff of general surgeons, and/or greater total hospital expenditures 
might be the critical factors affecting the per capita trauma death rate rather than the trauma center designation itself. To quantify the association of these other hospital resources with the per capita trauma death rate, multivariate analyses were performed. These other measures of hospital resources were not significantly associated with the per capita trauma death rates.

Of the medical system variables tested, county ALS certification was the most significant predictor of the per capita trauma death rate, followed by trauma center designation. Linear regression estimated parameters quantify the effect of the independent variable on the dependent variable. Given the value of the independent variable, we can estimate a predicted value for the dependent variable. In the current study, parameter estimates for trauma center and ALS training allowed estimates to be made of the potential impact of the presence of these factors on county per capita trauma death rates. Using the parameters estimated for multiple linear regression, the presence of ALS and a trauma center were associated with a decrease in the per capita trauma death rates of 1 to 2 per 10,000 population. Given that the mean county population ranges from 50,000 to 250,000 people, 5 to 25 lives could be saved per county per year. Trauma center designation, in contrast to other measures of hospital resources, was also associated with a decreased per capita trauma death rate. These results are consistent with the hypothesis that trauma centers save lives and that the majority of this effect occurs in the prehospital arena.

\section{SUMMARY}

Trauma remains a critical problem in America. Although other studies have evaluated the impact of trauma centers on outcome from trauma, these studies have generally been retrospective chart reviews of relatively small numbers of patients. To gain national support for trauma centers, a strong demonstration of the value of trauma centers is needed. The current study used two large, well-validated, population-based data bases to look at all the trauma deaths and hospitalizations in the state of North Carolina for the years 1988 to 1991. This study expanded our previous work by adding trauma hospitalization rates, prehospital death rates, and hospital death rates per county to the total per capita trauma death rates as measures of outcome. Similar to the results of other studies, a number of demographic and socioeconomic factors were found to be associated with increased per capita trauma death rates. These included measures of rural character, such as population density, per cent of unemployment, and per cent of the county population that is nonwhite.

Of the medical system variables tested, ALS training and trauma centers were consistently found to be the two most powerful predictors of the per capita trauma death rates. Other medical system factors, such as hospital size and clinical activity (represented by the number of admissions and the number of general surgeons), were not found to be predictors of county trauma death rates. The results of this study are consistent with the hypothesis that trauma centers significantly decrease trauma deaths and confirm the findings in our previous work, which show a decreased per capita trauma death rate associated with advanced life support (ALS) training.

\section{References}

1. Committee on Trauma Research, Commission on Life Sciences National Research Council and the Institute of Medicine. Injury in America. Washington, DC: National Academy Press, 1985; pp 1-15.

2. Thal ER, Rochon RB. Inner-city trauma centers: financial burdens or community saviors? Surg Clin North Am 1991; 71:209213.

3. United States General Accounting Office. Trauma Care. Lifesaving System Threatened by Unreimbursed Costs and Other Factors. Report to the Chairman, Subcommittee on Health for Families and the Uninsured, Committee on Finance, United States Senate, May 1991.

4. Roy PD. The value of trauma centers: a methodologic review. Can J Surg 1987; 30:17.

5. Rutledge R, Messick J, Baker CC, et al. Multivariate population based analysis of the association of county trauma centers with per capita county trauma death rates. J Trauma 1992; 3329-38.

6. Committee on Trauma of the American College of Surgeons. Resources for Optimal Care of the Injured Patient. Chicago: POB American College of Surgeons, 1990; pp 1-25.

7. Patetta MJ, Biddinger PW. Characteristics of drowning in North Carolina. Public Health Rep 1988; 103:406.

8. Cole TB, Patetta MJ. Hunting firearm injuries, North Carolina. Am J Public Health 1988; 78:1585.

9. Patetta MJ, Cole TB. A population-based descriptive study of house fire deaths in North Carolina. Am J Public Health 1990; 80:1116.

10. Rutledge $R$, Lalor A, Oller D, et al. The cost of not wearing seat belts: a comparison of outcome in 3,396 patients. Ann Surg 1993; 217:122-127.

11. Smith JS Jr, Martin LF, Young WW, et al. Do trauma centers improve outcome of non-trauma centers: the evaluation of regional trauma care using discharge abstract data and patient management categories. J Trauma 1990; 30:1533.

12. Kelly TJ, Westaby $S$. Trauma centers and the efficient use of financial resources. Br J Surg 1990; 77:1142.

13. Aprahamian C, Wolferth CC Jr, Darin JC, et al. Status of trauma center designation. J Trauma 1989; 29:566.

14. Lee G. Trauma center de-designation: a Los Angeles County update. J Emerg Nurs 1989; 15:20.

15. Oakes DD, Wilmot CB, Hall, et al. Benefits of early admission to a comprehensive trauma center for patients with spinal cord injury. Arch Phys Med Rehabil 1990; 71:637.

16. Martin GD, Coghill TH, Landercasper J, et al. Prospective analysis of rural interhospital transfer of injured patients to a referral trauma center. J Trauma 1990; 30:1014.

17. Larkin $\mathrm{H}$. Trauma center closings threaten other hospitals. Hospitals 1989; 63:22. 
18. Jacobs LM, Schwartz RJ. The impact of prospective reimbursement on trauma centers: an alternative payment plan. Arch Surg $1986 ; 121: 479$.

19. Koska MT. Many surgeons unwilling to staff trauma centers. Hospitals 1989; 63:46.

20. Waller JA, Payne SR, McClallen JM. Trauma centers and DRGs-inherent conflict? J Trauma 21989; 9:617.

21. Leikin JB, Frateschi LJ, Boston DA, et al. Effects of nonparticipation in trauma center system on emergency department utilization. J Emerg Med 1990; 8:545.

22. West JG, Trunkey DD, Lim RC. Systems of trauma care: a study of two counties. Arch Surg 1979; 114:455.

23. Payne SR, Waller JA. Trauma registry and trauma center biases in injury research. J Trauma 1989; 29:424.

24. Clemmer TP, Orme JF Jr, Thomas FO, et al. Outcome of critically injured patients treated at level I trauma centers versus full-service community hospitals. Crit Care Med 1985; 13:861.

25. Schwab CB, Young G, Civil I, et al. DRG reimbursement for trauma: the demise of the trauma center (the use of ISS grouping as an early predictor of total hospital cost). J Trauma 1988; 28:939.

26. Rutledge $\mathbf{R}$, Messick WJ. The association of trauma death and alcohol use in a rural state. $J$ Trauma 1992; 33:736-742.

27. Messick WJ, Rutledge R, Meyer AA. The association of advanced life support training and decreased per capita trauma death rates: an analysis of 12,417 trauma deaths. J Trauma 1992; 33:850-855.

28. Patsey T, Messick J, Rutledge R, et al. A population based, multivariate analysis of the association between 911 access and per capita county trauma death rates. Ann Emerg Med 1992; 21:11731178.

29. Rutledge $\mathrm{R}$, Lalor A, Oller $\mathrm{D}$, et al. The cost of not wearing seat belts: a comparison of outcome in 3,396 patients. Ann Surg 1993; 217:122-127.

30. Young W. The Impact of Emergency Medical Services on the Morbidity and Mortality of Trauma Patients. Final Report. Pittsburgh: Pittsburgh Research Institute, 1989.

31. Baker SP, Whitfield RA, O'Neill B. Geographic variations in mortality from motor vehicle crashes. N Engl J Med 1987; 316:13841387.

32. Gervin AS, Fischer RP. The importance of prompt transport in salvage of patients with penetrating heart wounds. J Trauma 1982; 22:443.

33. Mattox KL, Bickell W, Pepe PE, et al. Prospective MAST study in 911 patients. J Trauma 1989; 29:1104.

34. Smith JP, Bodai BI, Hill AS, et al. Pre-hospital stabilization of critically injured patients: a failed concept. J Trauma 1985; 25:575.

\section{Discussion}

DR. ROBERT E. CONDON (Milwaukee, Wisconsin): I enjoyed this presentation by Dr. Rutledge very much. It attempts to approach an issue of major concern in terms of health policy for this country-the continuing disparity between outcomes of trauma in the rural environment and in the urban environment.

In this study, Dr. Rutledge compared the crude total trauma death rates in 8 North Carolina counties that had trauma centers with 92 counties that didn't and concluded that the presence of the trauma center was associated with a significant decrease in the trauma death rate.

In some ways that's almost a self-fulfilling prophecy, and I don't question the conclusion. But I do want to raise some other questions about the study because careful analysis of epidemiologic studies of trauma potentially provides the insights that we'll need to guide development of appropriate medical system responses to the problem.

We're never going to get a trauma center in every rural county in America, so we need to do carefully stratified analyses to identify other factors that we can influence. In doing these analyses, it's essential to avoid an ecologic fallacy resulting from the bias inherent in the arbitrary process of aggregating epidemiologic data.

Now, in this study, the arbitrary classification of the data by county and by the presence or absence of a trauma center may in fact confound analysis of the data. Counties are political subdivisions that have little to do with human health or other similar factors that impact on the response to trauma, and the presence of a trauma center is largely a phenomenon of an urban environment. That's where the trauma centers are.

The urban environment is different from the rural environment. Automobile speeds are lower, response times are quicker, and the population in terms of the extremes of life tends to be underrepresented in the urban centers. Rural centers are overrepresented with the very young and the very old, who are more frail and who have a worse outcome from trauma.

It is these kinds of confounding factors, as well as the more societal factors which Dr. Rutledge has gone through, that may be very important in the analysis of data and in avoiding the ecologic fallacy.

Now, "ecologic fallacy" is an epidemiologic term, and it's still early on Saturday morning after Friday evening, but let me give by analogy an example of ecologic fallacy for which I am indebted to Dr. Mark Gottlieb. In Wisconsin, air quality varies a good bit from one county to another. Also, the number of cows per acre varies from one county to another. And it turns out that those Wisconsin counties with the highest density of cows per acre also have the best quality air. Would you conclude from that data that cows cause clean air? No, that would be a fallacy in Wisconsin. It would also be a fallacy in North Carolina.

I would like Dr. Rutledge to address the important issue of how he has adjusted and stratified his crude epidemiologic data to avoid falling into that sort of trap.

The second question I'd like to raise has to do with the prehospital death rates. Have you looked at the data in your abstract book? The difference between hospital death rate and total death rate I'm assuming is primarily related to the pre-hospital deaths. And the difference is 2 deaths per 100,000 people and it's identical in both those counties with trauma centers and those without.

That doesn't seem to fit the conclusion that counties with trauma centers have a lower pre-hospital death rate. I'd appreciate it if you could explore that issue in a little bit more detail with us.

Dr. ChARLes L. Rice (Dallas, Texas): I'd like to congratulate Dr. Rutledge and his colleagues on an excellent paper and a superb presentation and thank the Program Committee for putting a study such as this on the program for us.

As violence becomes increasingly recognized as a public health issue, it is clear that we must begin to take public health 